TUBERCULOSIS

\title{
Rates of drug resistance and risk factor analysis in civilian and prison patients with tuberculosis in Samara Region, Russia
}

\author{
M Ruddy, Y Balabanova, C Graham, I Fedorin, N Malomanova, E Elisarova, S Kuznetznov, \\ G Gusarova, S Zakharova, A Melentyev, E Krukova, V Golishevskaya, V Erokhin, I Dorozhkova, \\ F Drobniewski
}

Thorax 2005;60:130-135. doi: 10.1136/thx.2004.026922

\begin{abstract}
See end of article for authors' affiliations

Correspondence to:

Dr F Drobniewski,

Department of

Microbiology and

Infection, King's College

Hospital (Dulwich), London

SE22 8QF, UK; francis.

drobniewski@kcl.ac.uk
\end{abstract}

Received 18 April 2004 Accepted 18 October 2004

\begin{abstract}
Background: Tuberculosis (TB) and HIV rates continue to escalate in Russia, but true rates for drug resistance, especially multidrug resistant tuberculosis (MDR TB), are unknown. A study was conducted with the aims of identifying first line drug resistance, both in the civilian and prison sectors, for new and previously treated cases; and risk factors for the development of drug resistance.

Methods: A cross sectional survey was undertaken of 600 patients (309 civilians, 291 prisoners) with bacteriologically confirmed pulmonary TB over a 1 year period during 2001-2 in Samara Oblast, Russia. Results: The prevalence of isoniazid, rifampicin, streptomycin, ethambutol and pyrazinamide resistance in new TB cases (civilian and prison patients) was 38.0\%, 25.2\%, 34.6\%, 14.7\%, and $7.2 \%$, respectively. The prevalence of MDR TB was $22.7 \%, 19.8 \%$, and $37.3 \%$ in all new cases, new civilian cases, and new prison cases, respectively, with an overall prevalence of $45.5 \%$ and $55.3 \%$ in previously treated cases. Factors associated with resistance included previous TB treatment for more than 4 weeks, smoking (for isoniazid resistance), the presence of cavitations on the chest radiograph, and imprisonment. HIV was not associated with resistance in all patients. The rates of resistance were significantly higher in prisoners, with rate ratios (RR) of $1.9(95 \% \mathrm{Cl} 1.1$ to 3.2$)$ for MDR TB, $1.9(95 \% \mathrm{Cl} 1.1$ to 3.2$)$ for rifampicin, and 1.6 (95\% Cl 1.0 to 2.6$)$ for isoniazid.

Conclusions: Rates of first line drug resistance are high, particularly in prisoners and previously treated cases. TB control programmes should initially focus on standardised treatment to maximise cure, combined with measures to reduce institutional TB spread (particularly in prisons) coupled with early diagnosis of MDR TB to reduce the spread and development of resistance.
\end{abstract}

T rue rates of drug resistant tuberculosis $(\mathrm{TB})$ throughout the world remain unknown, particularly in regions where the TB burden is greatest. This has been due principally to methodological problems including the absence of longitudinal studies to detect trends, the failure to differentiate primary and acquired drug resistance in studies, the selection bias of many surveys, and the absence of high quality laboratory culture facilities. ${ }^{12}$

Russia is one of the WHO defined higher burden countries where $\mathrm{TB}$ remains a massive public health threat and an economic burden. ${ }^{2}$ The incidence and mortality of TB rose significantly in Russia at the end of the 20th century and the start of the new millennium (86.0/100 000 and 21.5/100 000 in 2002, respectively ${ }^{3-5}$ ), but there have been few internationally validated drug resistance surveys that could establish the true rates of resistance. A small number of pilot studies in different regions of Russia and other former republics showed high rates of drug resistant and multiple drug resistant TB (MDR TB: resistant to at least isoniazid and rifampicin). However, many of these surveys were limited to either small population samples or were restricted to prison or civilian patients only.

This cross sectional survey was conducted over 1 year in one of the most populous regions of Russia (Samara Oblast, population 3.3 million) located $1000 \mathrm{~km}$ south-east of Moscow in the Volga region. In 2002 the rates of new TB cases and mortality from TB were 74.9/100 000 and 12.9/ 100000 , respectively. ${ }^{7}$ A total of 2440 new cases of TB were registered in 2002, with the majority (70\%) diagnosed among the permanent resident population and among detainees in the prisons and the pre-trial detention centres. Tuberculosis is a significant problem in Samaran prisons (as in the whole of Russia), ${ }^{8}$ with an incidence rate in 2000 of 2200/100 000, ${ }^{4}$ with nearly 25000 prison inmates located in 19 prison institutions across the Oblast.

Infection with HIV is also a growing problem in Samara and in Russia as a whole. It has been suggested that 15-20\% of all people living with HIV/AIDS in Russia are in prison or detention facilities and, with nearly 1220000 people detained in prisons," Russia has one of the highest incarceration rates in the world. ${ }^{10}$

The aims of this detailed survey were to identify first line drug resistance in the civilian and prison sector in new and previously treated cases and to determine risk factors for the development of drug resistance in Samara.

This study is the largest encompassing demographic, clinical, social, and sexual health analyses of drug resistant TB in civilian and penitentiary patients in Russia.

\section{METHODS}

The study was designed in line with the 1994 WHO recommendations on drug resistance surveillance in TB with modifications. ${ }^{11}$ All 18 civilian TB dispensaries across the Samara region together with the prison TB hospital colony that admits all TB cases in the prison sector were included in the study. Prisoners account for approximately one third of TB patients. ${ }^{12}$ Consecutive TB patients aged over 18 years attending the institutions during the study periods were 


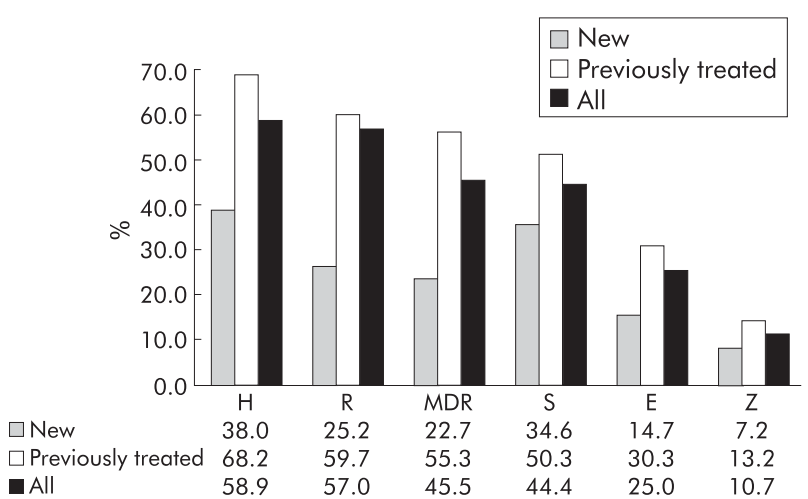

Figure 1 Overall first line drug resistance (\%) in patients with tuberculosis (civilians and prisoners) in Samara, Russia (weighted numbers). $H$, isoniazid; $R$, rifampicin; $M D R$, multidrug resistant; $S$, streptomycin; E, ethambutol; Z, pyrazinamide.

invited to take part and all participants gave informed written consent. Only those patients with bacteriologically proven TB who had viable Mycobacterium tuberculosis cultures on which drug susceptibility testing (DST) could be performed were included for risk factor analysis. The total time spent at each TB dispensary recruiting patients was calculated on the basis of the number of new cases notified in the previous year, focusing on new patients as the basis of the calculation (TB patients remain on the register for several years under the Russian system of follow up which influences the prevalence figure-in the year 2000 approximately 2400 new cases were detected but nearly 55000 cases were on the TB register ${ }^{4}$ ). Patients were interviewed by a team of trained Russian doctors and nurses who used a specially developed standardised questionnaire to collate clinical, demographic, and social data which were supplemented and verified with information from the medical notes.

The questionnaire was developed and approved by the Federal Tuberculosis Institutions (Moscow), Samara TB service, Samara ethics committee, and the Samara regional health department under whose auspices the study was conducted. Clinical staff examined patients for the presence of BCG and surgical scars. The sexual health section of the questionnaire was completed privately by patients using the principles established by the confidential investigation into sexual health in England and Wales. ${ }^{13}$ Radiological reports were analysed within the context of both the Russian classification system and descriptively (area of lungs affected and presence of cavitations).

\section{Bacteriological methods}

All sputum specimens were cultured on Lowenstein-Jensen media and the identity of $M$ tuberculosis (MTB) cultures was confirmed using a combination of growth, macroscopic and microscopic appearance, biochemical characterisation and/or DNA hybridisation (Accuprobe, Gen-Probe, CA, USA). Sputum specimens were obtained from all symptomatic individuals with pulmonary TB who were able to expectorate. Overall, 2.5 specimens were obtained from each patient. As part of the study the Regional Reference Laboratory was rebuilt and conducted microscopy, culture and drug susceptibility tests of all sputum samples received from the patients recruited into the study across the region. Extensive training in microscopy, culture and drug susceptibility testing were conducted with the staff at this and two other Samaran TB laboratories and also in Moscow and London. Quality control panels were exchanged between the three sites, Moscow and London before the start of the analysis.

Transport schedules were arranged to bring sputum from other TB centres rapidly across the region to these laboratories. Drug susceptibility testing was performed on all isolates for isoniazid, rifampicin, ethambutol, and streptomycin and on a sample of isolates for pyrazinamide resistance using the resistance ratio method on LowensteinJensen media. ${ }^{14}$ All cultures were tested in Samara and then two thirds of cultures were retested in London and in Moscow.

\section{Statistical analysis}

The data were analysed using Epi Info 6, Excel 97, and SPSS10 statistical packages. Pearson's $\chi^{2}$ statistics or Fisher's two tailed test were used to compare categorical variables and the Mann-Whitney $U$ test was employed to compare continuous variables. All questionnaire variables were examined in a univariate analysis and all variables with a $\mathrm{p}$ value of $\leqslant 0.01$ were included in a multivariate logistic regression analysis. Multivariate analysis was performed by binary logistic regression using forward stepwise and Wald statistical criteria; confounding effects were checked using a backwards regression analysis (variables were included and excluded from the model using a cut-off $p$ value of $<0.001$ ). Models were computed for all data, for civilians' and prisoners' data separately, and for new cases to determine risk factors for primary drug resistance.

\section{RESULTS}

Questionnaires were completed and medical notes reviewed on 3408 consecutive patients with pulmonary TB from the civilian and prison sectors. Analysis of risk factors for resistance was performed for 600 patients only (309 civilians and 291 prisoners) from whom expectorated sputum had been cultured producing viable $M$ tuberculosis cultures available for drug susceptibility testing. The participation rate was $98 \%$ (that is, only $2 \%$ declined to take part).

In the civilian system there were 269 men and 40 women, reflecting the male to female ratio attending with TB. Nearly

Table 1 Prevalence of drug resistance in new and previously treated civilian cases $(n=309)$ in Samara, Russia

\begin{tabular}{|c|c|c|c|c|}
\hline \multirow[b]{2}{*}{ Antibiotic } & \multicolumn{2}{|c|}{ New cases } & \multicolumn{2}{|c|}{ Previously treated cases } \\
\hline & $\begin{array}{l}\text { Resistant } \\
\text { (n) }\end{array}$ & $\begin{array}{l}\text { Resistant } \\
\text { (\% and } 95 \% \mathrm{Cl} \text { ) }\end{array}$ & $\begin{array}{l}\text { Resistant } \\
\text { (n) }\end{array}$ & $\begin{array}{l}\text { Resistant } \\
\text { (\% and } 95 \% \mathrm{Cl} \text { ) }\end{array}$ \\
\hline Isoniazid* & $32 / 95$ & 33.7 (24.7 to 43.6 ) & $147 / 214$ & 68.7 (62.2 to 74.6$)$ \\
\hline Rifampicin & $22 / 96$ & $22.9(15.3$ to 32.1$)$ & $129 / 214$ & 60.3 (53.6 to 66.7$)$ \\
\hline MDR TB & $19 / 96$ & 19.8 (12.7 to 28.7$)$ & $119 / 214$ & 55.6 (48.9 to 62.2 ) \\
\hline Streptomycin & $27 / 96$ & 28.1 (19.8 to 37.7$)$ & $107 / 214$ & 50.0 (43.3 to 56.6$)$ \\
\hline Ethambutol & $11 / 96$ & 11.5 (6.2 to 19.0$)$ & $64 / 214$ & 29.9 (24.0 to 36.3 ) \\
\hline Pyrazinamide $†$ & $3 / 49$ & $6.1(1.6$ to 15.8$)$ & $12 / 82$ & $14.6(8.2$ to 23.6$)$ \\
\hline
\end{tabular}


Table 2 Prevalence of drug resistance in new and previously treated prison cases $(n=291)$ in Samara, Russia

\begin{tabular}{|c|c|c|c|c|}
\hline \multirow[b]{2}{*}{ Antibiotic } & \multicolumn{2}{|c|}{ New cases } & \multicolumn{2}{|c|}{ Previously treated cases } \\
\hline & $\begin{array}{l}\text { Resistant } \\
\text { (n) }\end{array}$ & $\begin{array}{l}\text { Resistant } \\
\text { (\% and } 95 \% \mathrm{Cl} \text { ) }\end{array}$ & $\begin{array}{l}\text { Resistant } \\
\text { (n) }\end{array}$ & $\begin{array}{l}\text { Resistant } \\
(\% \text { and } 95 \% \mathrm{Cl})\end{array}$ \\
\hline Isoniazid & $42 / 67$ & $62.7(50.7$ to 73.6$)$ & $146 / 224$ & 65.2 (58.6 to 71.2 ) \\
\hline Rifampicin & $25 / 66$ & 37.9 (26.8 to 49.9$)$ & $126 / 224$ & 56.3 (46.7 to 62.6 ) \\
\hline MDR TB & $25 / 67$ & 37.3 (26.4 to 49.3$)$ & $120 / 224$ & $53.6(47.0$ to 60.0$)$ \\
\hline Streptomycin & $30 / 42$ & 71.4 (56.5 to 83.5$)$ & $117 / 224$ & 52.2 (45.7 to 58.7$)$ \\
\hline Ethambutol & $14 / 42$ & 33.3 (20.4 to 48.5$)$ & $72 / 223$ & 32.3 (23.4 to 38.6 ) \\
\hline Pyrazinamide & $3 / 23$ & 13.0 (2.8 to 33.6$)$ & $5 / 95$ & $5.3(1.7$ to 11.9$)$ \\
\hline
\end{tabular}

all the prisoners interviewed were young men. The median age for the overall population, civilian, and prison cases was 36 years (25-75th interquartile range (IQR) 27-47), 42 years (IQR 30-52), and 31 years (IQR 25-39), respectively. There was no significant difference between the median ages of prisoners and male civilians $(\mathrm{p}>0.05)$. The majority of patients were Russian (2804/3430, 81.7\%).

The rate of first line drug resistant TB in all cases (new and previously treated) was relatively high: across Samara Oblast the prevalence of MDR TB was $46.6 \%$ (95\% CI 42.6 to 50.6 ), of isoniazid resistance was $60.2 \%$ (95\% CI 56.2 to 64.0 ), and of rifampicin resistance was $49.8 \%$ (95\% CI 45.8 to 53.8 ). Resistance in new cases (both civilians and prisoners) was $38.0 \%$ (95\% CI 31.0 to 45.9 ) to isoniazid, $25.2 \%$ (95\% CI 19.1 to 32.4 ) to rifampicin, and $22.7 \%$ (95\% CI 17.0 to 30.0 ) for MDR TB. The rate of MDR TB among previously treated cases was $55.3 \%$ (95\% CI 50.2 to 59.7 ).

Many patients had MTB isolates resistant to streptomycin (34.6\% (95\% CI 27.2 to 43.0$)$ ) and $26.1 \%$ (95\% CI 22.6 to 29.8) had isolates resistant to ethambutol before starting TB therapy. Detailed rates of primary and acquired resistance among civilian and prison TB patients are shown in fig 1 and tables 1 and 2.

Previous studies have not attempted to measure pyrazinamide resistance and it is not routinely analysed in most countries. In this study we extended our analysis to pyrazinamide and found a relatively low level of resistance (7.2\% in new cases).

Primary resistance rates in prisoners were significantly higher for all first line drugs and MDR. The attributive risk of developing MDR TB in prisoners was $17.5 \%$ (95\% CI 2.2 to 32.8 ). Prisoners were nearly twice as likely to be resistant to isoniazid (rate ratio (RR) 1.9 (95\% CI 1.3 to 2.6$)$ ), rifampicin (RR 1.6 (95\% CI 1.0 to 2.6)), or to have MDR TB (RR 1.9 (95\% CI 1.1 to 3.2$)$ ), table 3 .

All variables were included in the univariate analysis (data not shown) and subsequently in the multivariate analysis if $\mathrm{p}<0.01$ (table 4 ). Multivariate analysis among new cases of MDR TB indicated that recreational drug use increased the chance of MDR TB disease threefold (OR 3.0, 95\% CI 1.1 to
7.9). Multivariate analysis also showed that current TB treatment, as well as the presence of cavitations on the chest radiograph, were associated with "any resistance". For isoniazid resistance male sex (analysis in civilian patients only), the presence of cavitations (advanced lung destruction), accompanying chronic obstructive pulmonary disease (COPD), and smoking were significant risk factors. Similar risk factors were identified for rifampicin resistance and, in addition, previous treatment at prison facilities for civilian patients and current long term treatment were associated with resistance.

Current TB treatment increased chances of MDR TB nearly threefold (OR 2.8; 95\% CI 1.2 to 6.5). A history of imprisonment was strongly associated with the presence of MDR TB strains. HIV infection was not associated with drug resistance: HIV positive individuals were less likely to have MDR TB or rifampicin resistant TB (OR 0.3 (95\% CI 0.1 to 0.8 ) and OR 0.3 ( $95 \%$ CI 0.1 to 0.7 ), respectively).

\section{DISCUSSION}

High secondary (acquired) MDR TB rates can indicate contemporary weakness of TB control programmes (including inadequate treatment regimens and/or poor adherence) leading to current transmission of resistant strains whereas high rates of resistance in new cases (particularly MDR TB) suggest problems in the past. ${ }^{2}$ Studies have focused on headline pulmonary MDR TB rates as these patients are difficult to treat, can remain infectious for prolonged periods, and are of great epidemiological importance.

Two international reports have summarised the results of surveys or ongoing surveillance from nearly 60 regions or countries. Data from only two of 89 Russian regions were included in the global analysis. ${ }^{2}$ Recent drug resistance studies in Russia documented high levels of primary and acquired resistance to first line drugs including MDR TB, ${ }^{15-20}$ but many of these surveys were confined to only civilian or prison populations. Rates of MDR TB varied from approximately $17 \%$ to $25 \% .{ }^{15-18}$ Nevertheless, there are regions with lower MDR TB rates-for example, rates of $6.6 \%$ were reported in a small region (Orel Oblast) although they were

\begin{tabular}{|c|c|c|c|c|c|}
\hline Antibiotic & $\begin{array}{l}\text { Resistant cases in } \\
\text { civilians }(\%)\end{array}$ & $\begin{array}{l}\text { Resistant cases in } \\
\text { prisoners (\%) }\end{array}$ & $\begin{array}{l}\text { Attributive risk (rate } \\
\text { difference) and } 95 \% \mathrm{Cl}\end{array}$ & $\begin{array}{l}\text { Rate ratio } \\
(95 \% \mathrm{CI})\end{array}$ & p value \\
\hline Isoniazid* & 33.7 & 62.7 & 29.0 (12.8 to 45.3$)$ & $1.9(1.3$ to 2.6$)$ & 0.001 \\
\hline Rifampicin & 22.9 & 37.3 & $14.4(-1.2$ to 30.0$)$ & $1.6(1.0$ to 2.6$)$ & 0.046 \\
\hline MDR TB* & 19.8 & 37.3 & $17.5(2.2$ to 32.8$)$ & $1.9(1.1$ to 3.1$)$ & 0.013 \\
\hline Streptomycin* & 28.1 & 71.4 & $43.3(25.2$ to 61.4$)$ & 2.5 (1.8 to 3.7$)$ & 0.001 \\
\hline Ethambutol* & 11.5 & 33.3 & 21.8 (4.6 to 39.2 ) & $2.9(1.4$ to 5.8$)$ & 0.02 \\
\hline Pyrazinamide & 6.1 & 13.0 & $6.9(-11.6$ to 25.4$)$ & $2.1(0.5$ to 9.8$)$ & 0.32 \\
\hline
\end{tabular}




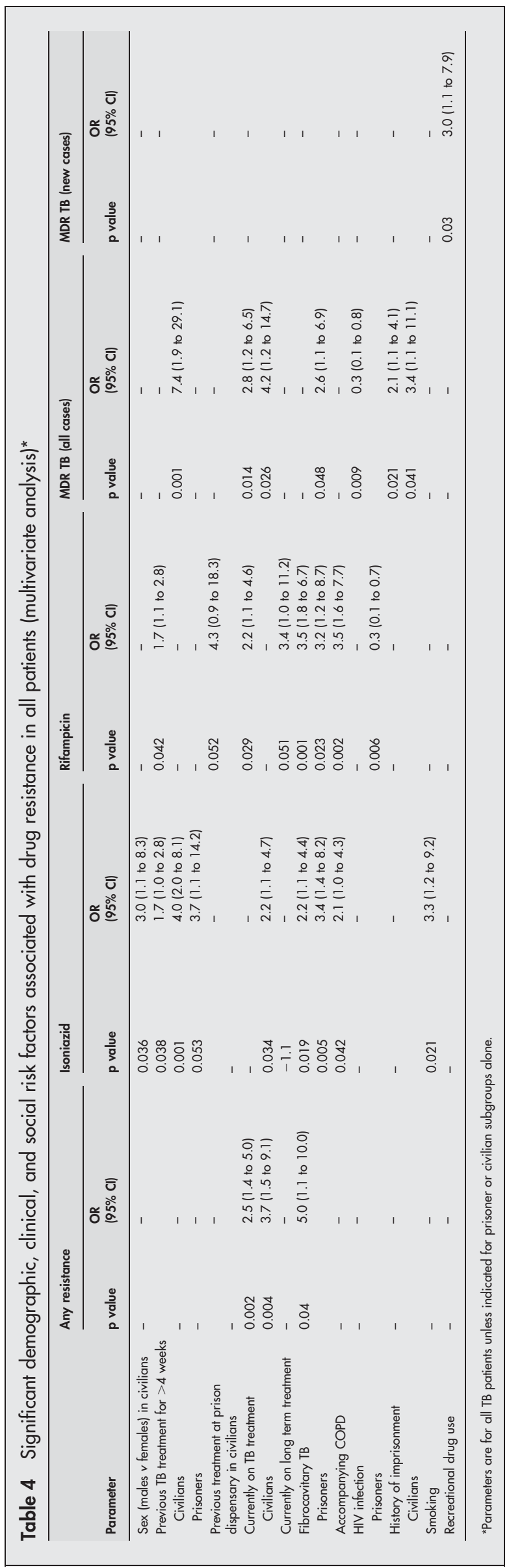

higher in prisoners (12\%) and re-treatment cases (prevalence ratio 8.5). This oblast is less typical in that it has a single central TB dispensary, little HIV infection, and a well established system of directly observed therapy. ${ }^{19} 20$ Nationally collected data under-represent the extent of drug resistance in Russia ${ }^{21}$ because of the use of non-standardised drug sensitivity testing techniques across different regions.

This study was conducted in the Samara region of Russia which has high reported rates of $\mathrm{TB}$ as well as a rapidly growing HIV epidemic. Patients with TB from both the civilian and prison sectors were recruited, including those with HIV co-infection. The Samara HIV epidemic emerged in 2000 among intravenous drug users and spread rapidly to a total of $21279 \mathrm{HIV}$ positive individuals by the beginning of 2004. Over three quarters of cases $(76.9 \%)$ were associated with intravenous drug use. Tuberculosis and HIV co-infection were seen in 450 cases in the region, ${ }^{4}$ and this figure is growing.

Primary resistance to isoniazid, rifampicin, and MDR TB across the whole study population was $38.0 \%, 25.2 \%$, and $22.7 \%$, respectively, with significantly higher rates among prisoners. However, no statistically significant differences were detected in the rates of resistance among previously treated civilian and prison cases. The overall prevalence of resistance was extremely high with nearly half of all cases resistant to at least one drug. These findings suggest long standing treatment problems including lack of standardisation of drug therapy and high rates of treatment interruption. Interviewed prisoners had frequently been in prison more than once and treatment might be interrupted due to poor compliance, early release of prisoners in amnesties (or through completion of sentences), or failure to attend the civilian TB service after release. A high loss to civilian follow up has been reported in Samara ${ }^{6}$ as elsewhere. ${ }^{22}$

As patients receive prolonged inpatient treatment, institutional spread of TB (and subsequently drug resistant TB and MDR TB) is likely in prisons but is also likely to occur within hospitals and other healthcare settings. This is supported by the significance of prior imprisonment as a risk factor for isoniazid and rifampicin resistance and MDR TB in civilian cases. Prison overcrowding and the inability to isolate resistant cases due to a lack of isolation facilities increase the transmission of resistant strains. The institutional spread of MDR TB has been well documented internationally and is of particular concern when many highly vulnerable individuals (such as those infected with HIV) congregate.

Knowledge of true drug resistance rates in the region is essential for developing appropriate treatment strategies. Drug resistant $\mathrm{TB}$, particularly MDR TB, is more difficult to treat and survival is poor with standard first line drug regimens. ${ }^{23}{ }^{24}$ Death rates in MDR TB cases vary from $0 \%$ to $37 \%$ in studies of HIV seronegative individuals and up to $89 \%$ in HIV seropositive populations. ${ }^{25}$ A recent study in Archangel, Russia reported a $16.7 \%$ death rate and $66.7 \%$ treatment failure rate among MDR TB cases, ${ }^{17}$ but in Orel treatment was successful overall although failure was associated with resistant cases, particularly in those with MDR TB. ${ }^{19}$ Even in high income countries such as the UK with access to individualised treatment, survival can be relatively low but treatment is more likely to be successful when three drugs to which the organism is susceptible are used. ${ }^{26}$

Overall multivariate analysis showed that being male, having a history of TB and previous or current treatment for more than 4 weeks, advanced disease with cavitation, and a history of imprisonment remained as highly significant risk factors for single drug resistance and MDR TB.

This study also examined the role of social factors in drug resistance. Smoking was found to be associated with 
isoniazid resistance but more evidence is needed to explain this association. Visiting public baths was a risk factor for MDR TB (although it failed to be significant on multivariate analysis). A possible explanation for this could be the transmission between a group of individuals (friends, neighbours) visiting public baths regularly for hygienic (poorer people living in wooden houses and hostels use public baths/saunas to maintain cleanliness) or for leisure purposes. Russian steam baths involve moisture laden air which could provide an environment supporting transmission of TB. (Anecdotally, Russians believe that inhalation in steam baths helps respiratory symptoms; this may stimulate attendance of infectious cases). Although recreational drug use was identified as a risk factor for drug resistance in new civilian cases (OR 2.9, 95\% CI 1.0 to $8.1, \mathrm{p}=0.035$ ), this just failed to be significant on mutivariate analysis for all cases. Analysis of any resistance showed that clinical symptoms such as weight loss (OR 0.5) and fever (OR 0.6) were less typical for resistant cases. HIV positivity was not associated with drug resistance but, as recreational drug use, the main route of HIV infection transmission is strongly associated with MDR TB in new cases, HIV co-infection is likely to become increasingly significant.

In Russia the TB epidemic is increasingly being accompanied by an HIV epidemic creating particular challenges for treatment and the control of institutional spread. The results of our study show that there is no evidence that immunocompromised individuals are more likely to be infected with a resistant strain offering a window of opportunity to prevent MDR TB taking hold in HIV positive patients.

While no one has doubted the importance of treatment of MDR TB cases (the most difficult) in industrialised countries, there has been debate as to whether treatment of MDR TB in low income countries might be an inefficient use of limited resources. ${ }^{27}{ }^{28}$ In middle income countries such as Russia the significant numbers of patients likely to require treatment raises difficult issues of cost effectiveness and cost benefit. Recent cost effectiveness analyses of an MDR TB treatment programme in Peru suggested that cases might be effectively treated under a standardised treatment approach for only $\$ 2400 .^{29}$

This study does suggest a number of realistic interventions that could be used to reduce the number of individuals developing MDR TB. Improving case detection and cure rates for drug sensitive TB and so preventing the emergence of clinical resistance has been facilitated by the introduction of internationally standardised treatment regimens including the use of fixed dose combination drugs. These are not only of proven efficacy but improve drug supply, minimising the change in drug regimen due to non-availability of drugs. Attempts to reduce loss to follow up of prisoners on release, including distribution of food packages to released prisoners at civilian dispensaries, have been introduced. Interventions to prevent nosocomial spread can be achieved by ensuring adequate isolation of infectious cases, reducing the number of prisoners overall and reducing the period of institutional care. Penal reforms have reduced the numbers of prisoners and the new treatment regimens have emphasised the role of outpatient care in the civil sector. Minimising disincentives to adhere to treatment (such as open ended payments for "disability") is more complex but needs addressing. Ultraviolet germicidal irradiation is widely available but infrastructure and organisational measures to replace lamps more regularly are needed to maintain effectiveness. Better masks and respirators are needed but, in the difficult financial circumstances, are unlikely to be widely available although better microbiological safety cabinets and masks have been introduced within the laboratory system.
Globally, projections of future incidence suggest that rates of drug resistance and MDR TB may climb ${ }^{30}$ and that concerted efforts to control MDR TB will be required over many years. The eastwards expansion of the European Union in 2004 means that there will be an increasing likelihood of patients with drug resistance entering the EU from Russia including Samara. Over the last decade there has been a substantial growth in tourist visits from Russia, educational exchange at secondary and tertiary levels, and the establishment of joint businesses as well as migration of certain ethnic groups. Internationally, borders remain porous and the industrialised world must support efforts to address drug resistance globally-if only out of enlightened self-interest.

\section{ACKNOWLEDGEMENTS}

M Ruddy and Y Balabanova contributed equally to the paper. The authors thank Professor M Shilova and the staff of the Moscow Federal Central Tuberculosis Research Institute and Research Institute for Phthsiopulmonology and Samara Regional TB service dispensaries and hospitals for their valuable advice and support in the design and implementation of the study. They are particularly grateful to the doctors, nurses, and patients who took part in the study.

\section{Authors' affiliations}

M Ruddy, Y Balabanova, F Drobniewski, HPA Mycobacterium Reference Unit, Department of Microbiology and Infection, Guy's King's and St Thomas' Medical School, King's College Hospital (Dulwich), London SE22 8QF, UK

Y Balabanova, I Fedorin, N Malomanova, E Elisarova, E Krukova,

Samara TB Service, Samara Oblast Dispensary, Samara City, Russian Federation

C Graham, Epidemiology and Statistics Core, Wellcome Trust Clinical Research Facility, Edinburgh, UK

S Kuznetznov, G Gusarova, Samara Oblast Health Department, Samara City, Russian Federation

S Zakharova, Samara City TB Service, Samara City, Russian Federation A Melentyev, Samara Prison TB Service, Samara City, Russian Federation

V Golishevskaya, V Erokhin, Central Tuberculosis Research Institute, Moscow, Russian Federation

I Dorozhkova, Russian Institute of Phthsiopulmonology of Moscow, Sechenov Medical Academy, Moscow, Russian Federation

This work was funded by the UK Department for International Development (CNTR 00 0134).

There is no conflict of interest.

\section{REFERENCES}

1 Vareldzis BP, Grosset J, de Kantor I, et al. Drug-resistant tuberculosis: laboratory issues. World Health Organization recommendations. Tuberc Lung Dis 1994;75:1-7.

2 World Health Organization. Anti-tuberculosis drug resistance in the world, Report from the WHO/IUALTD Global Project on Anti-tuberculosis Drug Resistance Surveillance, 1997:1 18-9.

3 Shilova MV. [Tuberculosis in Russia in the late 20th century]. Probl Tuberk 2001:5:8-13.

4 Drobniewski F, Balabanova Y, Ruddy M, et al. Medical and social analysis of prisoners with tuberculosis in a Russian prison colony: an observational study. Clin Infect Dis 2003;36:234-5.

5 Yerokhin VV, Punga VV, Rybka LN. Tuberculosis in Russia and the problem of multiple drug resistance. Ann NY Acad Sci 2001;953:133-7.

6 Coker RJ, Dimitrova B, Drobniewski F, et al. Tuberculosis control in Samara Oblast, Russia: institutional and regulatory environment. Int J Tuberc Lung Dis 2003;7:920-32.

7 Diuretic T, Herbert J, Drobniewski F, et al. Antibiotic resistant tuberculosis in the United Kingdom: 1993-1999. Thorax 2002;57:477-82.

8 Coninx R, Maher D, Reyes $\mathrm{H}$, et al. Tuberculosis in prisons in countries with high prevalence. BMJ 2000;320:440-2.

9 Alexandrova A. Russia: new criminal process code promises a more tolerant incarceration policy. Can HIV AIDS Policy Law Rev 2003;8:54.

10 Stern V. Problems in prisons worldwide, with a particular focus on Russia. Ann NY Acad Sci 2001;953:113-9.

11 World Health Organisation. Anti-tuberculosis drug resistance in the world. Report No 2: Prevalence and trends. Geneva: World Health Organisation, 2000.

12 Drobniewski FA, Balabanova YM. The diagnosis and management of multiple-drug-resistant-tuberculosis at the beginning of the new millenium. Int J Infect Dis 2002;6(Suppl 1):S21-31. 
13 Johnson AM, Mercer CH, Erens B, et al. Sexual behaviour in Britain: partnerships, practices, and HIV risk behaviours. Lancet 2001;358: 1835-42.

14 Canetti G, Fox W, Khomenko A, et al. Advances in techniques of testing mycobacterial drug sensitivity, and the use of sensitivity tests in tuberculosis control programmes. Bull WHO 1969:41:21-43.

15 Nechaeva OB, Skachkova El, Fomina NI. [Drug resistance of Mycobacterium tuberculosis in the Sverdlovsk Region]. Probl Tuberk 2002;9:8-11.

16 Vilianen MK, Vyshnevskiy BI, Otten TF, et al. Survey of drug-resistant tuberculosis in northwestern Russia from 1984 through 1994. Eur J Clin Microbiol Infect Dis 1998;17:177-83.

17 Toungoussova S, Caugant DA, Sandven P, et al. Drug resistance of Mycobacterium tuberculosis strains isolated from patients with pulmonary tuberculosis in Archangels, Russia. Int J Tuberc Lung Dis 2002;6:406-14.

18 Kimerling ME, Slavuckii A, Chavers S, et al. The risk of MDR-TB and polyresistant tuberculosis among the civilian population of Tomsk city, Siberia, 1999. Int J Tuberc Lung Dis 2003;7:866-72

19 Kherosheva T, Thorpe LE, Kiryanova E, et al. Encouraging outcomes in the first year of a TB control demonstration program: Orel Oblast, Russia. Int J Tuberc Lung Dis 2003:7:1045-51.

20 Spradling P, Drociuk D, McLaughlin S, et al. Drug-drug interactions in inmates treated for human immunodeficiency virus and Mycobacterium tuberculosis infection or disease: an institutional tuberculosis outbreak. Clin Infect Dis 2002;35:1106-12.

21 Sevast'ianova EV, Shul'gina MV, Puzanov VA, et al. [Analyzing the drug resistance of Mycobacterium tuberculosis in Russia's experimental areas introducing the $\mathrm{WHO}$ tuberculosis control programme]. Probl Tuberk 2002;12:11-4.

22 Drobniewski $\mathbf{F}$. Tuberculosis in prisons - forgotten plague. Lancet 1995;346:948-9

23 Quy HT, Lan NT, Borgdorff MW, et al. Drug resistance among failure and relapse cases of tuberculosis: is the standard re-treatment regimen adequate? Int $J$ Tuberc Lung Dis 2003;7:631-6.

24 Espinal MA, Kim SJ, Suarez PG, et al. Standard short-course chemotherapy for drug-resistant tuberculosis: treatment outcomes in 6 countries. JAMA 2000:283:2537-45.

25 Park MM, Davis AL, Schluger NW, et al. Outcome of MDR-TB patients, 19831993. Prolonged survival with appropriate therapy. Am J Respir Crit Care Med 1996; 153:317-24.

26 Drobniewski F, Eltringham I, Graham C, et al. A national study of clinical and laboratory factors affecting the survival of patients with multiple drug resistant tuberculosis in the UK. Thorax 2002;57:810-6.

27 Dye C, Espinal MA, Watt CJ, et al. Worldwide incidence of multidrug-resistant tuberculosis. J Infect Dis 2002;185:1197-202.

28 Coker $\mathbf{R}$. Should tuberculosis programmes invest in second-line treatments for multidrug-resistant tuberculosis (MDR-TB)? Int J Tuberc Lung Dis 2002;6:649-50.

29 Suarez PG, Floyd K, Portocarrero J, et al. Feasibility and cost-effectiveness of standardised second-line drug treatment for chronic tuberculosis patients: a national cohort study in Peru. Lancet 2002;359:1980-9.

30 Dye C, Williams BG, Espinal MA, et al. Erasing the world's slow stain: strategies to beat multidrug-resistant tuberculosis. Science 2002;295:2042-6.

\section{LUNG ALERT}

\section{Early aberrant gene expression in primary non-small cell carcinomas: a future diagnostic tool?}

$\Delta$ Smith SL, Gugger M, Hoban P, et al. S100A2 is strongly expressed in airway basal cells, preneoplastic and primary nonsmall cell lung carcinomas. Br J Cancer 2004;91:1515-24

$\mathrm{T}$

he S100A2 gene has previously been shown by this group to be significantly increased in non-small cell lung cancer. This study examined the expression of S100A2 in primary non-small cell lung carcinomas (NSCLC) with matched normal bronchial epithelium. Tumour tissue was obtained from 48 patients ( 37 men, 11 women) with resectable NSCLC (20 squamous cell, 24 adenocarcinomas, three large cell, and one poorly differentiated NSCLC) and matched with normal bronchial epithelial tissue from a tumour-free site in all but two patients. Reverse transcriptase polymerase chain reactions and immunohistochemical analysis were used to quantify the expression of S100A2 and allow consideration of its association with tumour histology, clinical outcome, and pre-neoplasia.

S100A2 was detected in the normal tissue of most patients but it was also strongly overexpressed (>2-fold) in $76 \%$ of tumour tissues compared with matched controls. Squamous cell carcinomas expressed S100A2 more frequently than adenocarcinomas $(\mathrm{p}<0.002)$, but no correlation was found between gene expression and overall survival or smoking history. S100A2 expression was also shown to be increased in apical bronchial epithelial cells in association with an increase in the degree of cellular abnormality $(\mathrm{p}<0.0001)$. In contrast, basal bronchial epithelial cells exhibited strong expression of S100A2 in both tumour tissues and matched controls (97\%). Supplemental analysis did not support previous identification of S100A2 as a tumour suppressor gene but did suggest a link between its expression and the transcriptional activator gene p63.

Early detectable gene expression in NSCLC may allow the future development of presymptomatic detection of lung cancer and therefore the opportunity for early therapeutic intervention leading to a significant reduction in lung cancer mortality.

S E A Fairbairn

Specialist Research Registrar, Department of Respiratory Medicine, Royal Gwent Hospital, South Wales, UK; docsara2001@yahoo.com 